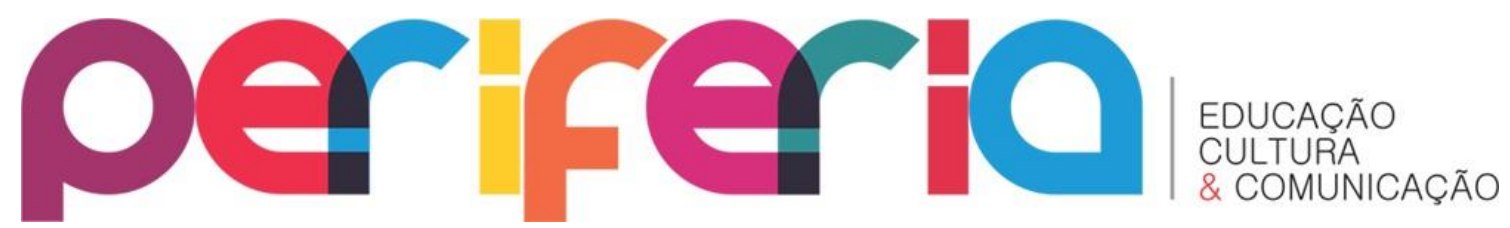

ISSN:1984-9540

DOI: 10.12957/ periferia.2020.55034

\title{
ROTEIRO DO FILME JOÃOSINHO DA GOMÉA - O REI DO CANDOMBLÉ (SEXTO TRATAMENTO)
}

Janaina Santos Oliveira ${ }^{1}$

Rodrigo da Silva Dutra²

\section{Resumo}

Conhecer a história de pessoas que foram importantes para a constituição de um lugar é fundamental para construir um senso de pertencimento de um território. 0 curta documentário Joãosinho da Goméa - O Rei do Candomblé traz Seu João como o narrador de sua própria história, de sua vida em Inhambupe no estado do Bahia até sua chegada a Duque de Caxias onde fundou - Terreiro da Goméa Caxiense. A pesquisa para construção deste roteiro foi baseada em artigos acadêmicos, publicações e jornais da época. Apesar de ser uma personalidade conhecida, não encontramos em nossa pesquisa nenhum outro filme que contasse a sua história. A inspiração cinematográfica veio do filme Alma do Olho (1973) de Zózimo Bulbul, onde ele narrou a história da população negra na diáspora sem dizer uma palavra, com uma fotografia universal e atemporal. Assim foi construído o roteiro desta história que originou o documentário.

Palavras-chave: Joãosinho da Goméa; Candomblé; Intolerância religiosa; Terreiro.

\section{MOVIE SCREENPLAY JOÃOSINHO DA GOMÉA - THE KING OF CANDOMBLÉ (SIXTH TREATMENT)}

\section{Abstract}

Knowing the history of people who were important for the constitution of a place is fundamental to build a sense of belonging to a territory. The short documentary Joãosinho da Goméa - O Rei do Candomblé brings Seu João as the narrator of his own history, of his life in Inhambupe in the state of Bahia until his arrival in Duque de Caxias where he founded Terreiro da Goméa Caxiense.

\footnotetext{
${ }^{1}$ Mestrado em Cultura e Territorialidades - PPCulT/UFF, Graduada em Comunicação Social - Publicidade e Propaganda - Universidade Veiga de Almeida, Pesquisadora do Laboratório de Experimentações Artísticas e Reflexões Criativas sobre Cidades, Saúde e Educação - LEARCC, do(a) Universidade do Estado do Rio de Janeiro. ORCID: https://orcid.org/0000-0001-5082-3134. E-mail janainaoly@gmail.com

${ }^{2}$ Mestre em Educação, Cultura e Comunicação em Periferias Urbanas - PPGECC/UERJ. Historiador - UERJ. Cineasta. ORCID: https://orcid.org/0000-0001-6479-0118. E-mail: rodrigohistoriador@gmail.com
}

Periferia, v. 12, n. 3, p. 253-267, set./dez. 2020 


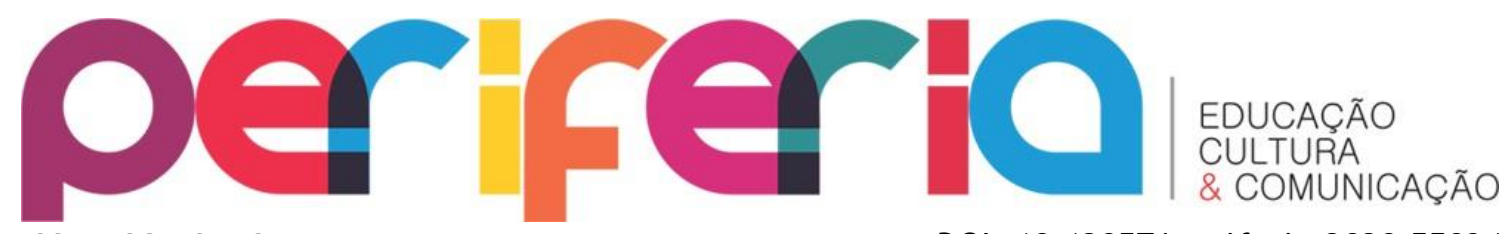

ISSN:1984-9540

DOI: $10.12957 /$ periferia.2020.55034

The research for the construction of this script was based on academic articles, publications and newspapers of the time. Despite being a well-known personality, we did not find in our research any other film that told his story. The cinematic inspiration came from the film Alma do Olho (1973) by Zózimo Bulbul, where he narrated the history of the black population in the diaspora without saying a word, with a universal and timeless photograph. This was how the script for this story was created, which originated the documentary.

Key-words: Joãosinho da Goméa; Candomblé; Intolerância religiosa; Terreiro.

\section{GUIÓN DE PELÍCULA JOÃOSINHO DA GOMÉA - EL REY DE CANDOMBLÉ (SEXTO TRATAMIENTO)}

\section{Resumen}

Conocer la historia de personas que fueron importantes para la constitución de un lugar es fundamental para construir el sentido de pertenencia a un territorio. El corto documental Joãosinho da Goméa - O Rei do Candomblé trae a Seu João como narrador de su propia historia, de su vida en Inhambupe en el estado de Bahía hasta su llegada al Duque de Caxias donde fundó Terreiro da Goméa Caxiense. La investigación para la construcción de este guión se basó en artículos académicos, publicaciones y periódicos de la época. A pesar de ser una personalidad conocida, no encontramos en nuestra investigación ninguna otra película que contara su historia. La inspiración cinematográfica vino de la película Alma do Olho (1973) de Zózimo Bulbul, donde narró la historia de la población negra en la diáspora sin decir una palabra, con una fotografía universal y atemporal. Así fue como se creó el guión de esta historia, que dio origen al documental.

Palabras-claves: Joãosinho da Goméa; Candomblé; Intolerância religiosa; Terreiro. 


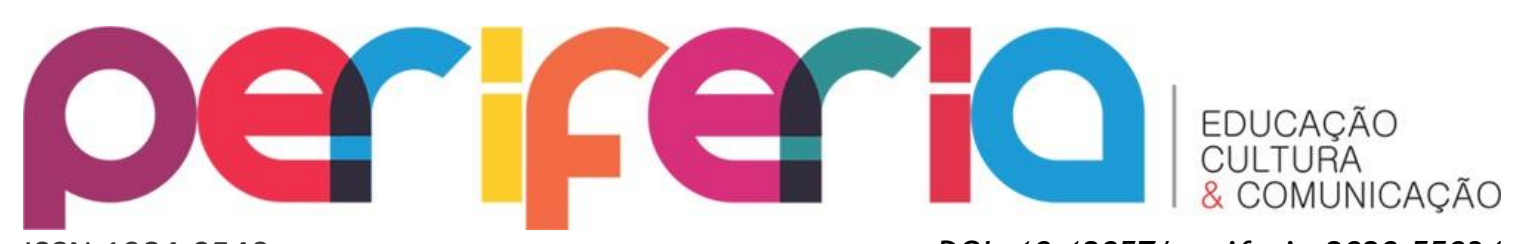

\section{EXT. DIA - TERREIRO DO JOÃOSINHO DA GOMÉA EM D. DE CAXIAS}

Grande Plano Geral, plongée, ao fundo Exu se desloca dançando ainda fora de foco, ele gira e dança com muita alegria em direção a câmera e aos poucos vai entrando em foco explorando toda a profundidade do lugar.

Se aproxima da câmera até tomar todo o enquadramento e este ficar completamente black.

Trilha Sonora: Bombagira, faixa 1, LP Joãosinho da Goméa

(0 local que foi o terreiro de Joãosinho da Goméa é uma "terra arrasada", sem plantas, apenas uma árvore resiste próximo aos escombros do que restou de sua casa, lembra mais um aterro sanitário, cheio de lixo, caco de vidro e outras porcarias misturadas a terra, repleto de cavalos e moleques é antagonicamente cinematográfica, amplo e amarronzado. Será usado para inserir os créditos iniciais)

CARTELA: JOÃOSINHO DA GOMÉA - O REI DO CANDOMBLÉ

INT. ESTÚDIO - APRESENTAÇÃO DO PERSONAGEM 


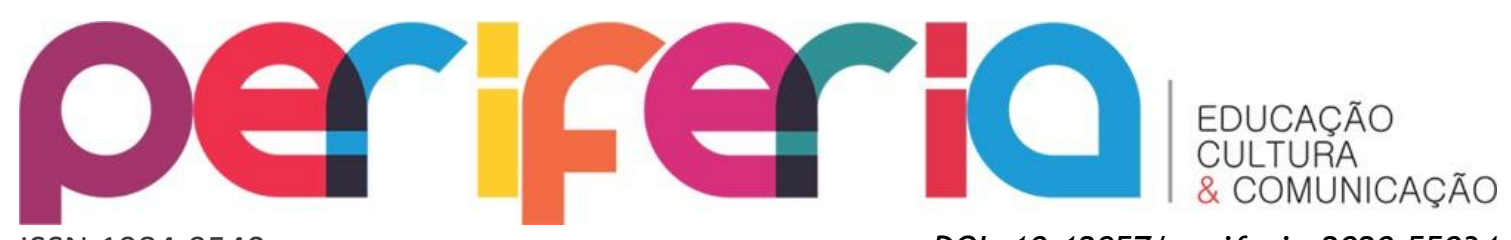

ISSN:1984-9540

DOI: $10.12957 /$ periferia.2020.55034 Imagem da sua silhueta sem revelar a personagem, seguidas de detalhes de olhos, boca, orelhas, braços, tronco.

Áudio de acervo de Joãosinho da Goméa relatando sua herança africana:

\author{
“Bem toda a minha descendência é \\ religiosa, eu nunca tive pretensão \\ nesse negócio de candomblé, nada \\ dessas coisas, nem compreendia tão \\ pouco. (...) Minha avó de fato é \\ africana, (...) ela aprendeu que estes \\ negócios de candomblé era assim, ela \\ largou as coisas que ela mesmo \\ compreendia e entendia e nunca dava \\ expansão aquilo." (ref. 1,07/1,52)
}




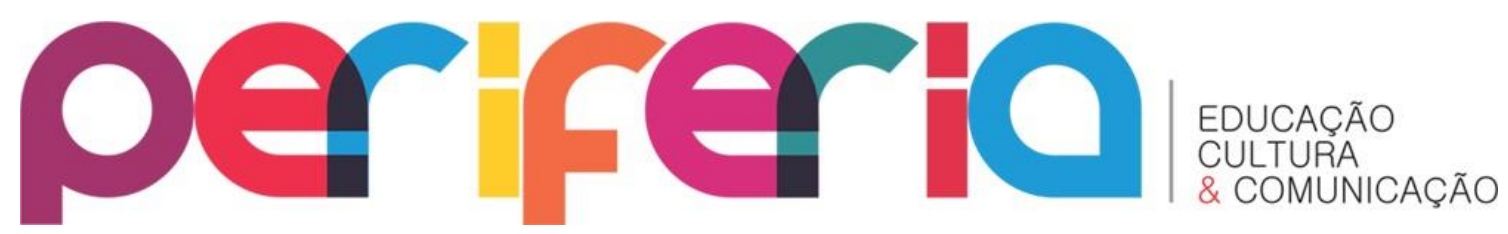

ISSN:1984-9540

DOI: 10.12957/periferia.2020.55034

INSERT - INHAMBUPE

Imagens de arquivo da cidade de Inhambupe: Igreja, praça principal, dia da bandeira, bar do Jacaré etc.

\title{
(Parallax ou Ken Burns Effect)
}

Áudio de acervo de Joãosinho da Goméa relatando seu local de origem e religião:

\author{
"Inhambupe no estado do Bahia. Então \\ minha mãe e meu pai são católicos, e \\ eu frequentava muito a igreja, \\ inclusive o padre naquela época tinha \\ uns sobrinhos que eram meus colegas de \\ escola e eles me convidaram para \\ ajudar a celebrar a missa, tanto que \\ eu aprendi a ajudar a celebrar a \\ missa. Ainda usei batinazinha vermelha \\ para ser coroinha." (ref. 0,34/1,06)
}




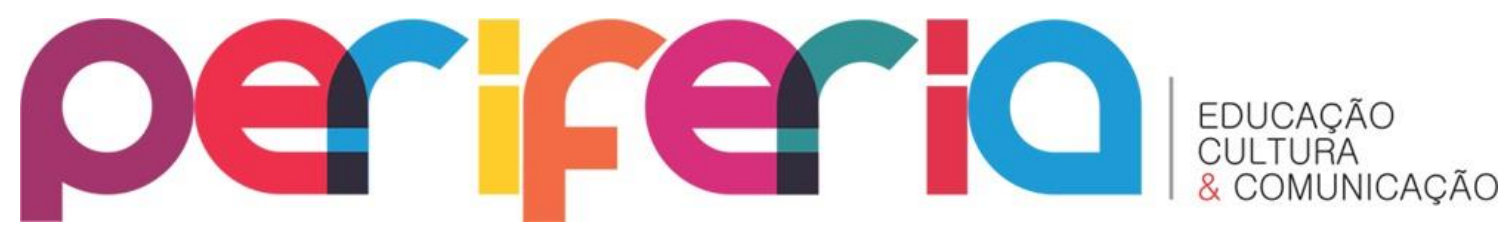

INT. ESTÚDIO - PEDRA PRETA

Plano Próximo de Joãosinho da Goméa que se retorce com dores de cabeça.

(o som é de trovoada, a iluminação

com "strobo" é intermitente,

pisca, ouvimos barulho de gemido.)

Joãosinho da Goméa aos poucos deixa de sentir as dores. Olha com complacência e a câmera recua vagarosamente em travelling frontal (out) até obter o plano inteiro do personagem que está nu em um fundo branco.

(A cena se ilumina em luz natural, o som de trovoada cessa)

Áudio de acervo de Joãosinho da Goméa relatando suas fortes dores de cabeça:

(começa a partir do momento que a cena se ilumina em (uz natural)

"Era uma dor de cabeça de doido, isso aqui em volta dos olhos ficava preto, mas preto como carvão e que a dor de cabeça não passava hora nenhuma. Hoje eu não vou dizer se foi o santo ou se foi mesmo doença o negócio é que eu recorri a vários médicos (...). Quanto mais remédio tomava pior ficava por que não dormia nem de noite, nem de dia hora nenhuma (...) Minha madrinha então me levou na casa do falecido Severiano ele é conhecido por Jubiabá (...) negócio era caso de santo" (ref.12,17) 


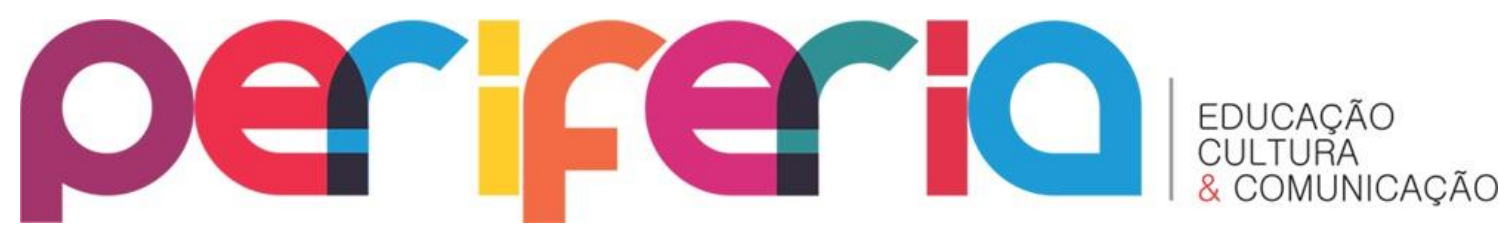

ISSN:1984-9540

DOI: $10.12957 /$ periferia. 2020.55034

Plano Médio. A câmera em trevelling (in) diagonal passeia no cenário branco com luz e se aproxima até Joãosinho da Goméa.

(CONTINUED)
(A luz se transforma para amarelo, azul e vermelho sendo projetada em partes específicas do cenário)

Áudio de acervo de Joãosinho da Goméa explica o aparecimento do caboclo Pedra Preta:

\footnotetext{
"Num dia que era até aniversário de minha madrinha (..)foi quando me pegou

o Pedra Preta (..) a primeira vez e julga-se hoje que é esse que eu vi naquela época das dores(..)então o pouco que ele teve ali ele falou conversou com aquele pessoal, atendeu um e atendeu outro e deixou dito que na próxima quarta-feira voltaria(..). Na próxima quarta-feira ao invés de vir as pessoas que ele mandou voltar, já veio o duplo, um por que falou com outro, outro por que disse vamos (..) e quando eu esclareci eu já estava com a casa numa condição que não dava mais pra conter o povo ali (..) Então daí eu me transferi pra Goméa."
}

Final do Traveling em Primeiro Plano. Ao mesmo tempo em que o áudio cessa Joãosinho da Goméa coloca seu cocar com penas e saúda 3 vezes: 


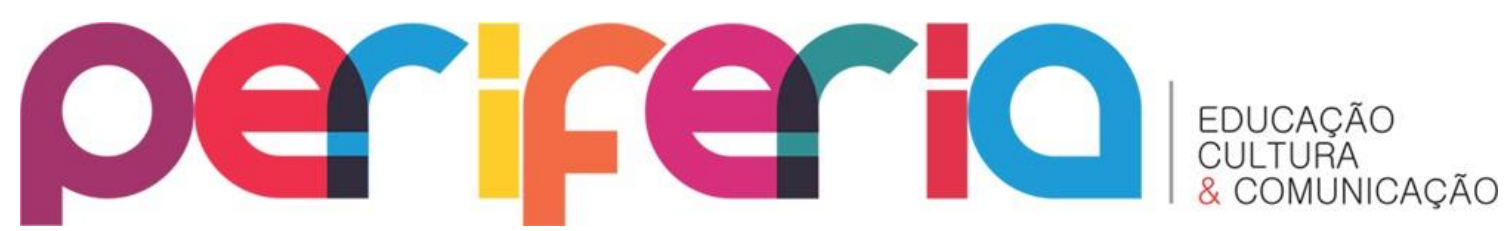

"Okê Caboclo! Okê Caboclo! Okê

Caboclo!"

INSERT - VINDA PARA CAXIAS / PRISÃO DE JOÃOSINHO

A sequência é composta com imagens de arquivo sobre a prisão de Joãosinho da Goméa quando chegou no RJ.

(Técnica de Parallax ou Ken Burns

Effect)

Áudio de acervo de Joãosinho da Goméa relatando sobre a vinda para Duque de Caxias:

“eu não pensei em vir para o Rio,

Kilondirá que é umas filhas de santo

(...) ela mudou-se para o rio e trouxe

o santo dela. Então queria justamente

fazer a obrigação do santo e mandou me

convidar como pai de santo dela para

vir fazer a obrigação. Então eu vim, como uma viagem de 15 dias um mês para

fazer a obrigação de kilondirá

(..)Assim que eu cheguei veicularam

aquela notícia: Joãosinho da Gomea ta

no Rio, jornal da, um vai me abraçar

outro vai me visitar, um tirei uma

consulta, um tirei uma obrigação,

atendia um outro voltava me trazia

outra pessoa, quando eu vi tava com

nove meses (..) nessa volta minha ja

Periferia, v. 12, n. 3, p. 253-267, set./dez. 2020 


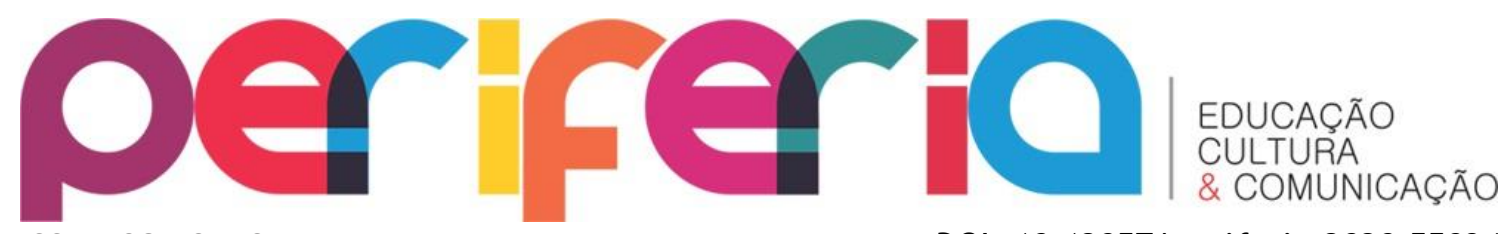

ISSN:1984-9540

DOI: $10.12957 /$ periferia. 2020.55034

fui para um casa que aluguei pra mim

(..) então aluguei uma casa maior

dessa aqui da Castro Alves (..) aí foi

que comprei isso aqui." (ref. 37,27)

EXT. DIA - TERREIRO DO JOÃOSINHO DA GOMÉA EM D. DE CAXIAS

(Ainda com o som da frase anterior

ressoando)

Várias imagens, com vários enquadramentos explorando o "visual" do que restou do terreiro em Duque de Caxias. Imagens também com a presença do Joãosinho da Goméa que passa pelo quadro

(Pode-se usar a técnica de

Cinemagraph)

O Som é direto, captando o som ao redor. 


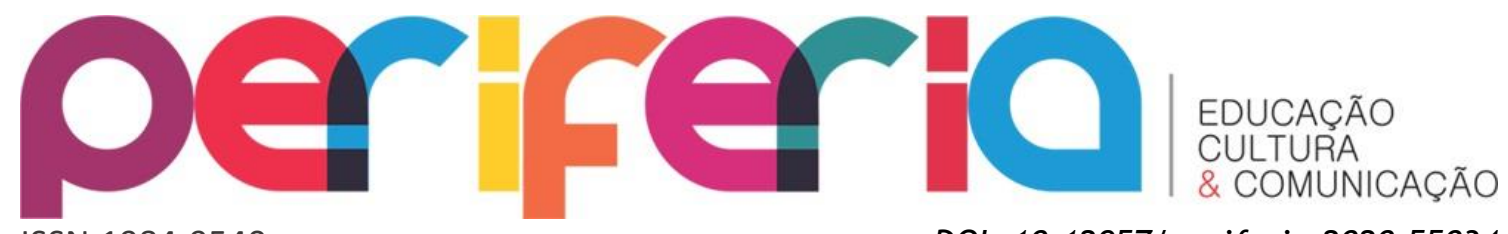

INT. ESTÚDIO. CANTA PARA OXOSSI

Trilha Sonora: som faixa 3 do disco de Joãosinho da Goméa que canta para Oxossi.

Fundo Branco, os enquadramentos são em detalhes de um manequim sendo vestido com as roupas de Oxossi. Aparecem mãos negras dentro do quadro que ajudam a se vestir, criando planos esteticamente interessantes.

(A luz natural no intuito de demonstrar o contraste entre $o$ corpo negro, o branco do cenário e as marcas do tempo das roupas de Joãosinho)

Plano Geral. Manequim completamente vestido de Oxossi e Joãosinho da Goméa dançando para Oxossi ao redor.

(A luz muda para diversos tons de verde câmera permanece parada e Joãosinho personagem dança sendo entoado pelo espetáculo de luz) 


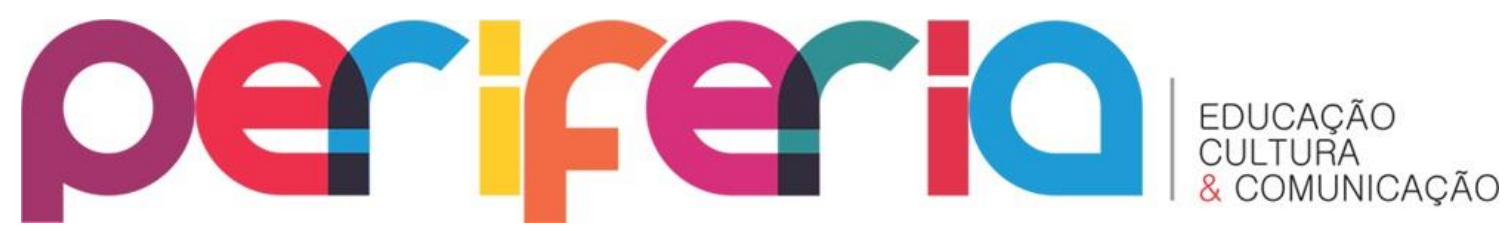

\title{
INSERT - MACUMBA PARA INGLÊS VER
}

A sequência é composta com imagens de manchetes de jornal em que Joãosinho da Goméa aparece ao lado de autoridades políticas e diplomáticas além de grandes nomes da cultura e da arte nacional que frequentavam a sua Goméa.

(Técnica de Parallax ou Ken Burns

\section{Effect)}

Áudio narrado em estilo de cinejornal retirado de uma matéria que detrata a pessoa de Joãosinho da Goméa:

\author{
"Que fim levou a autoridade moral de \\ tantas entidades civilizadoras e \\ educativas? (...) A Voragem da \\ libertinagem sexual arrasou a família, \\ destruiu o magistério, expulsou o \\ sacerdócio, extinguiu a cultura, \\ acabou com a urbanidade, liquidou com \\ o respeito e ridicularizou a moral. \\ Enquanto o país apodrece (...) os \\ lares desmoronam e o bacanal campeia, \\ exalta-se um Zabaneiro descarado como \\ Joãozinho da Gomeia enquanto se \\ esquecem dos heróis e sábios, mártires \\ e santos. É o fim da Pátria. 0 \\ apodrecimento do país"3
}

\footnotetext{
${ }^{3}$ Diário de Notícias, 26 de Fevereiro de 1956.
} 


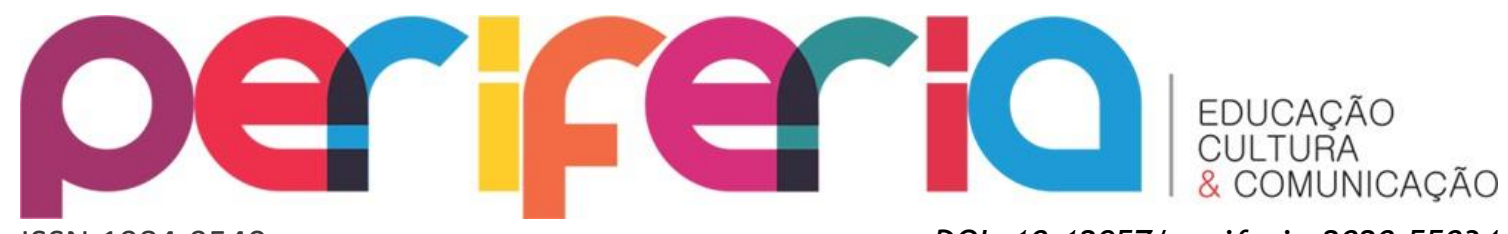

INT. ESTÚDIO - CANTA PARA IANSÃ

Plano Geral, Joãosinho da Goméa caminha do fundo do cenário para a boca de cena, se aproxima da câmera, nas mãos está com uma roupa ou um objeto de lansã.

(0 caminhar de Joãosinho é de reverência, quando se aproxima da câmera, apresenta como sagrados os objetos a ela)

Plano detalhe das roupas objetos.

Plano Geral, Joãosinho da Goméa repete o desfile com todos os objetos

(Para cada roupa objeto em detalhe aparece um letreiro descrevendo o nome da peça)

Plano Geral. Joãosinho da Goméa caminha do fundo para a boca de cena. Durante o caminhar tira a camisa de ração se aproxima da câmera e a utilizando como espelho passa batom, coloca seu brincos e joga os cabelos na câmera.

(Esse caminhar é completamente

diferente do anterior, agora

caminha como se estivesse em um

desfile, sensualizando)

CORTE SECO 


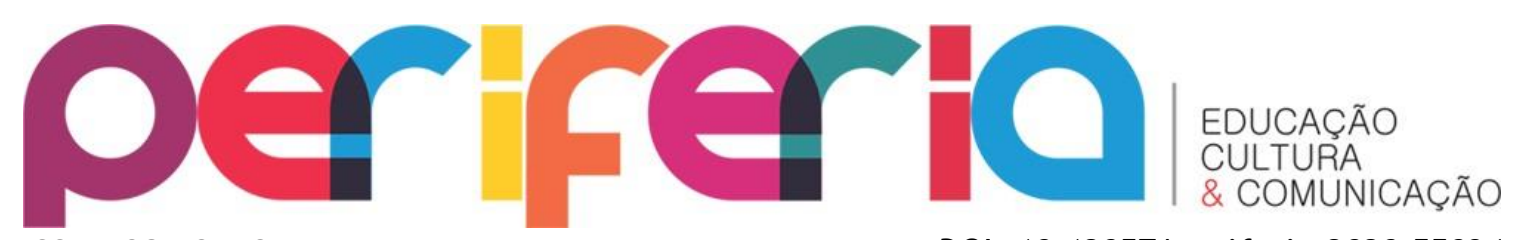

ISSN:1984-9540

DOI: $10.12957 /$ periferia. 2020.55034

EXT. DIA - FEIRA DE CAXIAS - ARLETE (DRAG QUEEN)

(no mesmo movimento dos cabelos da

sequência anterior temos uma

truncagem)

Joãosinho da Goméa aparece na feira da Cidade de Duque de Caxias montada de Arlete interagindo de forma performática com as pessoas.

Trilha Sonora: música Renunciei de Emilinha Borba.

Plano Geral, Joãosinho da Goméa caminha em direção à câmera.

Voz Over do personagem Joãosinho da Goméa:

“Eu não consigo me imaginar atualmente como apenas um elemento à parte do cenário afro-brasileiro, se o candomblé assumiu uma postura de espetáculo de luz e cores foi graças a minha roça da Gomeia, não posso acreditar que digam que eu desmoralizo ou desmoralizei o candomblé apenas por por gostar de enfeitar meus Orixás, ou brincar no carnaval, afinal estou vivo e se cheguei até aqui foi graças à minha personalidade e autenticidade, mais pelo menos tenho uma recompensa perante todo este bafafá, ocupei o meu lugar no mundo e quem estiver 


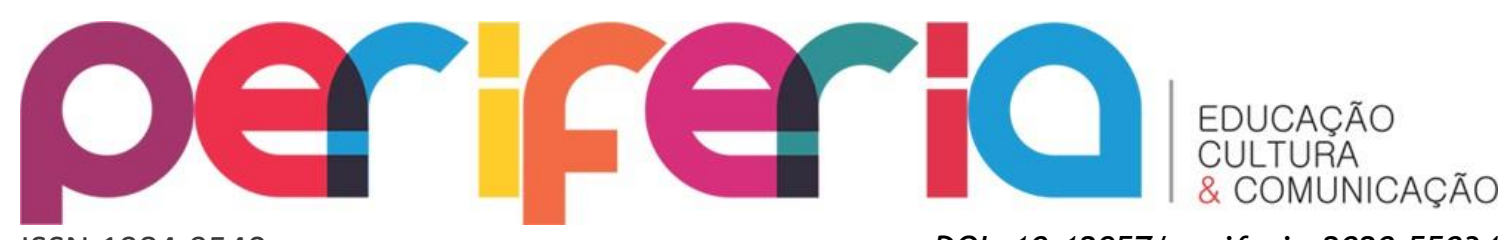

ISSN:1984-9540

DOI: $10.12957 /$ periferia.2020.55034 incomodado que venha falar comigo."4

Plano Próximo, fala para a câmera

"Afinal sou ou não sou o Rei do

Candomblé?"5

CUT TO BLACK

INSERT - CARTELAS

Desde os anos 1980 o Terreiro de Joãosinho da Goméa esta sob um impasse.

Governos querem fazer uma creche no local, porém movimentos religiosos e culturais preferem um centro cultural.

O local continua abandonado.

Sobem os créditos finais.

\section{REFERÊNCIAS}

GAMA, Elizabeth Castelano. Mulato, Homossexual e Macumbeiro: que rei e este? Trajetória de João da Goméia (1914-1971). Série Recôncavo da Guanabara, Volume 2. Duque de Caxias, Rj. APPH - CLIO, 2014.

\footnotetext{
${ }^{4}$ NASCIMENTO, Andrea. De São Caetano a Caxias: um estudo de caso sobre a trajetória do Rei do Candomblé Joãosinho da Goméa. Monografia (Licenciatura em História) - Universidade do Estado do Rio de Janeiro, 2003, p.42

${ }^{5}$ Idem
}

Periferia, v. 12, n. 3, p. 253-267, set./dez. 2020 


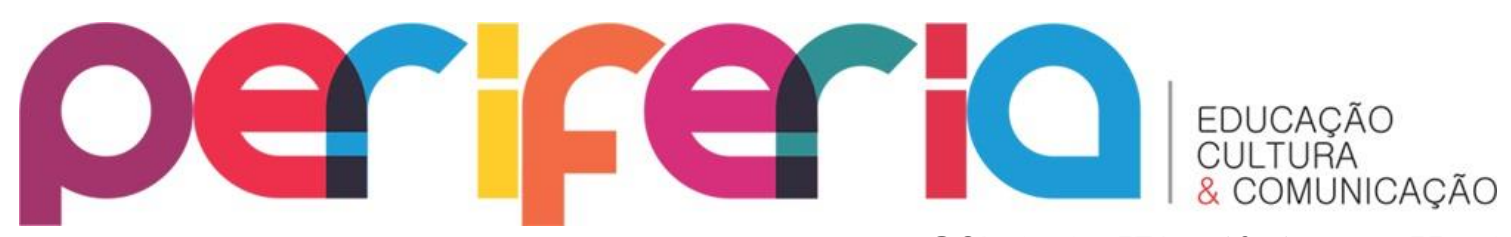

ISSN:1984-9540

DOI: $10.12957 /$ periferia.2020.55034

MENDES, Andrea. Vestidos de realeza: contribuições centro-africanas no candomblé de Joãozinho da Goméia, 1937-1967, Dissertação de Mestrado, IFCH/Unicamp.

NORONHA, Taís Fernanda. Joãozinho da Goméia: História e Memória de um babalorixá. Dissertação (Mestrado) - Humanidades, Culturas e Artes. UNIGRANRIO, 2017.

NASCIMENTO, Andrea. De São Caetano a Caxias: um estudo de caso sobre a trajetória do Rei do Candomblé Joãosinho da Goméa. Monografia (Licenciatura em História) - Universidade do estado do Rio de Janeiro, 2003.

Arquivo de Som. Ile Ase lya Atara Magba Gisele Omindarewa. Gentilmente cedidos por Leonardo Efunbode 